\title{
Whole Body Arginine Metabolism and Nitric Oxide Synthesis in Newborns with Persistent Pulmonary Hypertension
}

\author{
L. CASTILLO, T. DeROJAS-WALKER, Y. M. YU, M. SANCHEZ, T. E. CHAPMAN, D. SHANNON, \\ S. TANNENBAUM, J. F. BURKE, AND V. R. YOUNG
}

\begin{abstract}
Laboratory of Human Nutrition, Clinical Research Center [L.C., Y.M.Y., M.S., T.E.C., V.R.Y.], and
Division of Toxicology [T.D.R.-W., S.T.], Massachusetts Institute of Technology, Boston, Massachusetts 02139; Shriners Burns Institute, Boston Massachusetts 02114 [L.C., Y.M.Y., T.E.C., V.R.Y.]; and Pediatric and Neonatal Intensive Care Units and Children's Service, Departments of Pediatrics [L.C., M.S.], Pediatric Pulmonary Care [D.S.], and Surgery [J.F.B.], Massachusetts General Hospital,
\end{abstract} Harvard Medical School, Boston, Massachusetts 02114

\section{ABSTRACT}

Despite the potential relevance of the L-arginine-nitric oxide (NO) pathway in the pathophysiology of pulmonary hypertension, no in vivo studies of the kinetics of arginine and NO have been conducted previously in this population. The terminal guanidino $\mathrm{N}$-atom of L-arginine is the precursor for $\mathrm{NO}$, which is oxidized to the stable inorganic nitrogen oxides, nitrite $\left(\mathrm{NO}_{2}{ }^{-}\right)$ and nitrate $\left(\mathrm{NO}_{3}{ }^{-}\right)$. Thus, synthesized $\mathrm{NO}$ is detected in serum or urine as $\mathrm{NO}_{2}^{-}$and $\mathrm{NO}_{3}{ }^{-}$. The purpose of this investigation was to compare studies of whole body arginine metabolism twice in nine patients with persistent pulmonary hypertension of the newborn (PPHN), using a primed constant i.v. infusion of L- $\left[\right.$ guanidino- $\left.{ }^{15} \mathrm{~N}_{2}, 5,5^{2} \mathrm{H}_{2}\right]$ arginine and $\mathrm{L}-\left[5,5,5^{2} \mathrm{H}_{3}\right]$ leucine, first during acute pulmonary vasoconstriction and again during convalescence, and thereby to characterize quantitative aspects of whole body arginine kinetics and NO production, as estimated from the rate of transfer of the ${ }^{15} \mathrm{~N}$-guanidino-label of arginine to urinary nitrate $\left({ }^{15} \mathrm{NO}_{3}{ }^{-}\right)$. Arginine flux rates were $84.1 \pm 8.6$ $\mu \mathrm{mol} \cdot \mathrm{kg} \cdot{ }^{-1} \mathrm{~h}^{-1}$ (mean $\pm \mathrm{SEM}$ ) during acute pulmonary hypertension and increased to $125 \pm 13.2(p<0.05)$ during conva- lescence, whereas leucine fluxes were unchanged $(168.5 \pm 15$ versus $178.8 \pm 10.2 \mu \mathrm{mol} \cdot \mathrm{kg} \cdot{ }^{-1} \mathrm{~h}^{-1}$ ), and comparable to those reported in healthy newborns. During convalescence total urinary nitrate excreted increased by $66 \%(p<0.05)$, urinary ${ }^{15} \mathrm{NO}_{3}{ }^{-}$ increased from $0.29 \pm 0.07$ to $0.74 \pm 0.15 \mu \mathrm{mol} \cdot \mathrm{d}^{-1}(p<$ $0.05)$, and the rate of plasma arginine conversion to NO increased from $10.3 \pm 2.2$ to $45.6 \pm 13 \mu \mathrm{mol} \cdot \mathrm{d}^{-1}(p<0.05)$. This study indicates a decreased plasma arginine utilization for whole body NO synthesis during the acute vasoconstrictive state of PPHN and suggests that arginine availability may become an important factor in NO formation. (Pediatr Res 38: 17-24, 1995)

\section{Abbreviations}

PPHN, persistent pulmonary hypertension of the newborn NO, nitric oxide

eNOS, nitric oxide synthase

$\mathbf{A a D O}_{2}$, alveolo-arterial oxygen gradient

ECMO, extracorporeal membrane oxygenation

A.P.E., atom percent excess
PPHN is an acute vascular maladaptation to extrauterine life, characterized by reactive pulmonary vasoconstriction, causing extrapulmonary shunting of blood across fetal channels and critical hypoxemia. Remodeling of the pulmonary arteries has been observed in some patients with PPHN (1). The etiology of this disorder is uncertain, but a role for altered NO production, a recently discovered key regulator of vascular tone (2-4),

Received October 10, 1994; accepted February 27, 1995.

Correspondence and reprint requests: Leticia Castillo, M.D., Pediatric and Neonatal Intensive Care Units, Massachusetts General Hospital, Ellison 317, Fruit Street, Boston MA 02114.

Supported by a Research Grant from the American Lung Association, with additional support from NIH Grants DK 15856, RR88 (CRC Core Grant), and CA-26731 and the Shriners Hospital for Crippled Children Grants No. 15897 and 15843. must be considered. NO is produced in the pulmonary and systemic arteries of newborn animals (5) and contributes to the postnatal vasodilation of the pulmonary circulation $(6,7)$. NO is synthesized in the endothelial cells, through the action of eNOS, and diffuses into subjacent vascular smooth muscle, where it binds to its molecular target, the prosthetic heme group of soluble guanylyl cyclase, forming nitrosyl proteins (8). This process activates guanylyl cyclase, augmenting levels of the second messenger, cGMP (8). Intracellular elevation of cGMP levels activates cGMP-dependent protein kinases, leading to phosphorylation of proteins and inhibition of intracellular calcium release and/or influx through calcium channels. This mechanism is believed responsible for NO-induced vasorelaxation (8). 
The terminal guanidino $\mathrm{N}$-atom of $\mathrm{L}$-arginine is the precursor of NO, which is synthesized in cells by a cytokine-induced, high output L-arginine-NO pathway as well as a constitutive low output pathway (3). NO formed by either pathway undergoes oxidative degradation to the stable inorganic nitrogen oxides, nitrite $\left(\mathrm{NO}_{2}{ }^{-}\right)$and nitrate $\left(\mathrm{NO}_{3}{ }^{-}\right)$. In the in vivo system $\mathrm{NO}_{2}{ }^{-}$is oxidized to $\mathrm{NO}_{3}{ }^{-}$via hemoglobin, thus $\mathrm{NO}$ can be eventually detected in serum or urine as $\mathrm{NO}_{3}{ }^{-}(9,10)$.

Despite the biochemical importance of arginine as the precursor for NO, little is known about the in vivo regulation of arginine metabolism or how it varies during human pathophysiology. It has been shown that in some pathologic states, such as hypercholesterolemia (11), intimal hyperplasia post-balloon catheterization injury $(12)$, or hypoxia $(13,14)$, endothelial dysfunction may be reversed or attenuated by administration of $\mathrm{L}$-arginine, the precursor of NO.

Arginine, via ornithine, is also the precursor for polyamines (spermine, spermidine, and putrescine). These low molecular weight cations play an important role in the pulmonary arteries' remodeling during chronic hypoxemia (15-17). It appears, then, that these two important metabolites of arginine (NO and polyamines) are related to the main pathophysiologic events of PPHN: vasoconstriction and remodeling of the pulmonary arteries.

In this study, we examined whole body arginine and protein metabolism and NO production twice in infants with PPHN, first during acute pulmonary vasoconstriction and again during convalescence. We used a primed constant i.v. infusion of $\mathrm{L}-\left[{ }^{15} \mathrm{~N}\right]$ guanidino-labeled arginine and $\mathrm{L}-\left[{ }^{2} \mathrm{H}_{3}\right]$ leucine to characterize quantitative aspects of arginine and protein kinetics in these patients. NO production was estimated by the rate of transfer of the $\left[{ }^{15} \mathrm{~N}\right]$ guanidino label of arginine to urinary ${ }^{15} \mathrm{NO}_{3}{ }^{-}$. Due to arginine's precursor role for NO, we hypothesized that the L-arginine-NO metabolic pathway is altered during PPHN, resulting in a decreased rate of NO synthesis and therefore pulmonary vasoconstriction. We wished to address the following questions. 1) Is whole body arginine and protein metabolism different during the acute phase of PPHN when compared to convalescence? 2) Is the utilization of plasma arginine for whole body NO synthesis altered during PPHN?

\section{METHODS}

Patients. Nine sequential critically ill newborns with a diagnosis of PPHN confirmed by echocardiogram were investigated. The echocardiogram showed right to left shunting in all patients. Two patients (nos. 3 and 8 ) were shunting only through the ductus arteriosus, and the remaining seven patients were shunting through the foramen ovale and the ductus arteriosus. Pulmonary artery pressure was estimated by measurement of the doppler tricuspid regurgitation velocity jet and an assumed right atrial pressure of 10 , in patients without continuous right atrial pressure measurement. Seven patients had suprasystemic and two patients had systemic pulmonary artery pressure. The mean \pm SEM systolic pulmonary pressure was $46 \pm 1.8$ with a range of 37 to 54 Torr. Seven patients also had a diagnosis of meconium aspiration, one patient had blood aspiration, and one patient had primary PPHN. Patients with liver or renal failure, those treated with any nitrite-nitrate containing medication, or those with evidence of infection were excluded. The clinical characteristics of the patients are described in Table 1. All patients were outborn and transferred to the Neonatal Intensive Care Unit at the Massachusetts General Hospital. The patients were first studied within $24 \mathrm{~h}$ after admission, during acute hypoxemia with an $\mathrm{AaDO}_{2}$ of 81 $\pm 1.9 \mathrm{kPa}(609 \pm 7$ Torr, mean $\pm \mathrm{SEM})$, at $3.1 \pm 0.3 \mathrm{~d}$ of age, and again during convalescence, $\mathrm{AaDO}_{2} 19.5 \pm 0.9 \mathrm{kPa}(146$ \pm 4 Torr), at $6.9 \pm 0.7 \mathrm{~d}$ of age. We used the Neonatal Physiologic Stability Index (18) and the Therapeutic Intervention Score System (19) to assess the severity of disease and the

Table 1. Clinical characteristics of patients with PPHN studied for arginine metabolism

\begin{tabular}{|c|c|c|c|c|c|c|c|c|}
\hline Patient & $\begin{array}{l}\text { Gestational } \\
\text { age (wk) }\end{array}$ & $\begin{array}{l}\text { Weight } \\
\text { (kg) }\end{array}$ & Diagnosis $^{a}$ & Treatment & $\begin{array}{l}\text { Age on acute } \\
\text { study (d) }\end{array}$ & $\begin{array}{c}\mathrm{AaDO}_{2} \text { acute } \\
\text { study }(\mathrm{mm} \mathrm{Hg})\end{array}$ & $\begin{array}{c}\text { Age on } \\
\text { convalescent } \\
\text { study (d) }\end{array}$ & $\begin{array}{c}\mathrm{AaDO}_{2} \\
\text { convalescent } \\
\text { study (mm Hg) }\end{array}$ \\
\hline 1 & 40 & 2.7 & $\begin{array}{l}\text { PPHN } \\
\text { Mec Asp }\end{array}$ & $\begin{array}{l}\text { ECMO } \\
\mathrm{V}-\mathrm{A}^{b}\end{array}$ & 5 & 656 & 10 & 162 \\
\hline 2 & 39 & 3.4 & $\begin{array}{l}\text { PPHN } \\
\text { Mec Asp }\end{array}$ & $\begin{array}{l}\text { ECMO } \\
\text { V-A }\end{array}$ & 5 & 625 & 10 & 172 \\
\hline 3 & 40 & 2.9 & $\begin{array}{l}\text { PPHN } \\
\text { Blood Asp }\end{array}$ & Conventional & 3 & 590 & 9 & 146 \\
\hline 4 & 39 & 4.2 & $\begin{array}{l}\text { PPHN } \\
\text { Mec Asp }\end{array}$ & $\begin{array}{l}\text { ECMO } \\
\text { V-A }\end{array}$ & 3 & 612 & 6 & 140 \\
\hline 5 & 38 & 3.2 & $\begin{array}{l}\mathrm{PPHN} \\
\mathrm{Mec} \text { Asp }\end{array}$ & Conventional & 2 & 605 & 6 & 137 \\
\hline 6 & 39 & 3.3 & $\begin{array}{l}\text { PPHN } \\
\text { Mec Asp }\end{array}$ & $\begin{array}{l}\text { ECMO } \\
\text { V-A }\end{array}$ & 3 & 620 & 7 & 147 \\
\hline 7 & 37 & 2.9 & PPHN & Conventional & 2 & 600 & 5 & 151 \\
\hline 8 & 37 & 2.7 & $\begin{array}{l}\text { PPHN } \\
\text { Mec Asp }\end{array}$ & Conventional & 3 & 578 & 7 & 124 \\
\hline 9 & 42 & 3.1 & $\begin{array}{l}\text { PPHN } \\
\text { Mec Asp }\end{array}$ & Conventional & 2 & 603 & 6 & 142 \\
\hline Mean \pm SEM & $38.9 \pm 0.5$ & $3.2 \pm 0.1$ & & & $3.1 \pm 0.3$ & $609 \pm 7$ & $6.9 \pm 0.7$ & $146 \pm 4$ \\
\hline
\end{tabular}

${ }^{a} \mathrm{Mec}$, meconium; Asp, aspiration.

${ }^{b}$ V-A, veno-arterial. 
degree of therapeutic intervention required in these patients. The Neonatal Physiologic Stability Index score for the acute state was $7.7 \pm 1.9$ (mean \pm SEM) and for convalescence was $2.8 \pm 0.3$. The Therapeutic Intervention Score System score for the acute stage was $45.2 \pm 5.1$ and for the convalescence $11.1 \pm 2.3$. All patients were initially hyperventilated, sedated, and given muscle relaxants during the acute state. All patients were critically ill requiring resuscitation with i.v. fluids. Six of them, patient nos. $1,2,4,5,6$, and 9 , required the use of two inotropic agents (dopamine and dobutamine in all but patient no. 2, who received dopamine and epinephrine). Patient nos. 3 and 7 required one inotropic agent (dopamine); patient no. 8 did not receive vasoactive drugs but required frequent i.v. fluid boluses. Four patients met ECMO criteria (20) and received veno-arterial ECMO upon arrival to the NICU at the Massachusetts General Hospital. Convalescence was defined by resolution of the right to left shunt with an $\mathrm{AaDO}_{2}$ less than 26 $\mathrm{kPa}(200 \mathrm{Torr})$ and ventilator settings appropriate for extubation: fraction of inspired oxygen of 0.4 or less, peak inspiratory pressure $20 \mathrm{~cm}$, positive end expiratory pressure $5 \mathrm{~cm}$, and rate $<10$ breaths/min. On the ECMO patients convalescence was defined as above, after ECMO had been discontinued.

Study Protocol. The study protocol was approved by the Subcommittee on Human Studies of the Massachusetts General Hospital. Written informed consent was obtained from each patient's parents. All patients received a 4-h primed, constant i.v. infusion of L-[ guanidino- $\left.{ }^{15} \mathrm{~N}_{2}, 5,5-{ }^{2} \mathrm{H}_{2}\right]$ arginine and $\mathrm{L}-\left[5,5,5^{2} \mathrm{H}_{3}\right]$ leucine (99 atoms \%, Tracer Technologies Inc., Somerville, MA). The priming doses were 11.2 and 8.4 $\mu \mathrm{mol} \cdot \mathrm{kg}^{-1}$, and the constant infusion rates were 11.2 and 8.4 $\mu \mathrm{mol} \mathrm{kg} \cdot{ }^{-1} \mathrm{~h} \cdot-1$, respectively, for arginine and leucine. Leucine was used to provide a comparative index of the overall status of amino acid metabolism (21). Verification of isotopic purity was obtained before the infusion study. Labeled tracers were confirmed to be sterile and pyrogen-free before use. Both tracer solutions were infused at a rate of $2.5 \mathrm{ml} \cdot \mathrm{h}^{-1}$ in all patients. We used the arterial line as the sampling source and a central venous line for tracer infusion. In the ECMO patients the isotopes were infused via the venous cannula placed in the internal jugular vein, at the pre-membrane site for the first study. During the second study, a central or peripheral venous line was used for tracer infusion, and blood was sampled from an arterial line. Isotope tracers were infused by means of a calibrated syringe pump (Harvard Apparatus, Natick, MA).
Blood samples were obtained at $0,120,180,210$, and $240 \mathrm{~min}$, to measure plasma isotopic enrichment of both amino acid tracers. Blood samples were placed in tubes containing heparin and centrifuged immediately, and plasma was stored at $-80^{\circ} \mathrm{C}$ until analysis. Twenty four-hour urine collection beginning with the tracer infusion study was obtained under sterile conditions via a Foley catheter, and sterility was confirmed by a negative urine culture.

Nutritional support. All patients received variable levels of protein and energy intake with a nitrate-free total parenteral nutrition (Table 2). The composition of the amino acid mixture used (Novamine $11.4 \%$, Clinitec, Deerfield, IL), has been previously reported (22). The duration of nutritional support previous to the acute tracer infusion was variable $(0.6 \pm 0.3 \mathrm{~d})$, with patient nos. $1,5,6,7$, and 9 remaining on nothing by mouth during the first infusion study. All patients were receiving parenteral nutrition for $4 \pm 0.4 \mathrm{~d}$ during the second tracer infusion study.

Analytical methods. We used $300 \mu \mathrm{l}$ of plasma to determine the isotopic enrichment of $\left[{ }^{15} \mathrm{~N}_{2}\right]$ arginine and $\left[{ }^{2} \mathrm{H}_{3}\right]$ leucine by gas chromatography-mass spectrometry as previously described (23), all enrichments were determined against calibration standards, and values are expressed as mole fractions above the value for blood drawn before tracer administration.

A complete 24-h urine collection was obtained for ${ }^{15} \mathrm{~N}$ enrichment and total nitrate determinations. Urine was collected in dark polyethylene bottles containing sodium hydroxide and stored at $-20^{\circ} \mathrm{C}$ until analyzed. The ${ }^{15} \mathrm{~N}$ enrichment of urinary nitrate was measured by converting nitrate to nitrobenzene, as previously described (24). Urinary nitrate was measured utilizing an automated procedure (24).

Calculations. We used the standard steady state isotope dilution equation to determine plasma arginine $\left(\mathrm{Q}_{\mathrm{Arg}}\right)$ and leucine $\left(\mathrm{Q}_{\text {Leu }}\right)$ flux as follows (25):

$$
\mathrm{Q}=\mathrm{i} \cdot\left[\frac{\mathrm{Ei}}{\mathrm{Ep}}\right]-1
$$

where $\mathrm{i}$ is the rate of the tracer infusion $\left(\mu \mathrm{mol} \cdot \mathrm{kg}^{-1} \mathrm{~h}^{-1}\right)$ and Ei and Ep are the isotopic enrichments of the infusate and plasma amino acid, respectively. The constant -1 corrects for the tracer infused. Plasma leucine enrichment, not ketoisocaproic acid, was used to estimate the leucine flux.

Table 2. Energy and protein intake in patients with PPHN during vasoconstriction and convalescence

\begin{tabular}{|c|c|c|c|c|c|c|c|c|}
\hline \multirow[b]{2}{*}{ Patient } & \multicolumn{2}{|c|}{ Glucose $\left(\mathrm{mg} \cdot \mathrm{kg}^{-1} \cdot \mathrm{min}^{-1}\right)$} & \multicolumn{2}{|c|}{ Protein $\left(\mathrm{g} \cdot \mathrm{kg}^{-1} \cdot \mathrm{d}^{-1}\right)$} & \multicolumn{2}{|c|}{ Lipid $\left(g \cdot \mathrm{kg}^{-1} \cdot \mathrm{d}^{-1}\right)$} & \multicolumn{2}{|c|}{ Energy $\left(\mathrm{kcal} \cdot \mathrm{kg}^{-1} \cdot \mathrm{d}^{-1}\right)$} \\
\hline & Acute & Convalescent & Acute & Convalescent & Acute & Convalescent & Acute & Convalescent \\
\hline 1 & 6.5 & 7.5 & 0.0 & 0.8 & 0.0 & 1.0 & 37.4 & 64.1 \\
\hline 2 & 6.9 & 8.2 & 0.9 & 0.8 & 1.0 & 2.0 & 52.2 & 68.4 \\
\hline 3 & 5.9 & 6.2 & 1.0 & 1.3 & 1.2 & 3.0 & 46.9 & 67.7 \\
\hline 4 & 8.9 & 8.6 & 2.2 & 0.9 & 1.5 & 3.0 & 73.4 & 80.0 \\
\hline 5 & 7.1 & 7.8 & 0.0 & 1.3 & 0.0 & 2.0 & 40.8 & 68.0 \\
\hline 6 & 6.3 & 7.2 & 0.0 & 1.7 & 0.0 & 2.5 & 36.2 & 70.7 \\
\hline 7 & 6.9 & 6.5 & 0.0 & 1.6 & 0.0 & 1.5 & 39.7 & 57.1 \\
\hline 8 & 7.4 & 7.7 & 1.0 & 1.6 & 1.0 & 3.0 & 55.5 & 77.7 \\
\hline 9 & 6.5 & 7.0 & 0.0 & 1.5 & 0.9 & 2.7 & 37.4 & 70.5 \\
\hline Mean \pm SEM & $6.9 \pm 0.3$ & $7.4 \pm 0.2$ & $0.57 \pm 0.2$ & $1.2 \pm 0.1$ & $0.62 \pm 0.2$ & $2.3 \pm 0.2$ & $46.6 \pm 3.8$ & $69.3 \pm 2.1$ \\
\hline
\end{tabular}


The rate of urinary ${ }^{15} \mathrm{NO}_{3}{ }^{-}$excretion $\left(\mu \mathrm{mol} \cdot \mathrm{d}^{-1}\right)$ was derived by the following equation:

${ }^{15} \mathrm{NO}_{3}{ }^{-}$excretion

$$
=\frac{\text { total urinary } \mathrm{NO}_{3}{ }^{-}\left(\mu \mathrm{mol} \cdot \mathrm{d}^{-1}\right) \times \text { urinary }{ }^{15} \mathrm{~N} \text { A.P.E. }}{100}
$$

where total urinary $\mathrm{NO}_{3}{ }^{-}$is the amount of nitrate excreted in urine and enrichment of urinary ${ }^{15} \mathrm{~N}$ is expressed as A.P.E. (23).

The percentage of the $\left[{ }^{15} \mathrm{~N}_{2}\right]$ arginine tracer infused that was used for labeling NO was calculated as follows:

$\%\left[{ }^{15} \mathrm{~N}_{2}\right]$ Arg tracer infused to NO

$$
=\frac{{ }^{15} \mathrm{NO}_{3}{ }^{-} \text {excretion }\left(\mu \mathrm{mol} \cdot \mathrm{d}^{-1}\right)}{{ }^{15} \mathrm{~N}_{2} \text { Arg tracer infused }\left(\mu \mathrm{mol} \cdot \mathrm{d}^{-1}\right)} \times 100
$$

where ${ }^{15} \mathrm{NO}_{3}{ }^{-}$excretion is the amount of labeled $\left[{ }^{15} \mathrm{~N}\right]$ nitrate excreted in urine (Equation 2) and $\left[{ }^{15} \mathrm{~N}_{2}\right] \mathrm{Arg}$ is the amount of guanidino-labeled arginine tracer infused (prime plus the 4-h tracer infusion), expressed in $\mu \mathrm{mol} \cdot \mathrm{d}^{-1}$.

The rate of conversion of plasma arginine to $\mathrm{NO}\left(\mathrm{Q}_{\mathrm{Arg} \rightarrow \mathrm{NO}}\right.$; $\mu \mathrm{mol} \cdot \mathrm{d}^{-1}$ ) was derived as follows:

$$
\mathrm{Q}_{\mathrm{Arg} \rightarrow \mathrm{NO}}=\% \text { Arg tracer infused to } \mathrm{NO} \times \mathrm{Q}_{\mathrm{Arg}}
$$

where $\%\left[{ }^{15} \mathrm{~N}_{2}\right]$ Arg tracer infused to NO is determined as above (Equation 3), wherein $\mathrm{Q}_{\mathrm{Arg}}$ is the plasma arginine flux expressed as $\mu \mathrm{mol} \cdot \mathrm{d}^{-1}$ (Equation 1).

The rates of whole body protein turnover (synthesis and breakdown) were obtained assuming the leucine content of whole body mixed protein to be $361.3 \mu \mathrm{mol} / \mathrm{gram}$ of protein and from nitrogen balance $\left(\mathrm{g} \mathrm{N} \cdot \mathrm{kg}^{-1} \mathrm{~d}^{-1} \times 6.25\right)(26)$.

Data analysis. Results are presented as mean \pm SEM. Primary and derived values were tested for significance between acute illness and convalescence using a paired $t$ test with $p<0.05$ taken as significant. The relationship between arginine intake and the percentage of ${ }^{15} \mathrm{~N}_{2}$ tracer infused, used for NO formation, was evaluated by least squares linear regression analysis. An SAS program (27) was employed for statistical analysis.

\section{RESULTS}

During the 4-h continuous tracer infusion period a steady state level of isotopic enrichment of both the plasma leucine and arginine pools was achieved in our patients (Fig. 1). There was a tendency for plasma arginine and for leucine enrichment to increase toward the end of the 4-h period when patients were studied during acute pulmonary vasoconstriction. For all nine patients the mean coefficients of variation for plateau plasma isotope enrichment, based on samples drawn during the last $2 \mathrm{~h}$, were 13.3 and $13.9 \%$ for $\mathrm{L}$-[ guanidino ${ }^{15} \mathrm{~N}_{2}, 5$, $\left.5^{2} \mathrm{H}_{2}\right]$ arginine, and 3.7 and $5.8 \%$ for $\mathrm{L}-\left[{ }^{2} \mathrm{H}_{3}\right]$ leucine during PPHN and convalescence, respectively. From these isotopic enrichments, plasma arginine and leucine kinetics were calculated (Tables 3 and 4). Arginine enrichments were lower $(p<$ 0.05 ) during convalescence than in the acute phase of illness.

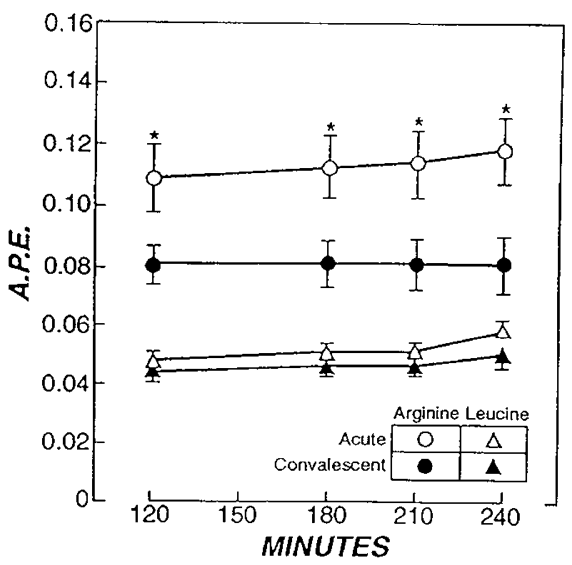

Figure 1. Plasma isotopic enrichment of $\mathrm{L}_{-}\left[\right.$guanidino- $\left.{ }^{15} \mathrm{~N}_{2}, 5,5^{2} \mathrm{H}_{2}\right]$ arginine and $\mathrm{L}-\left[5,5,5^{2} \mathrm{H}_{3}\right]$ leucine during a 4-h i.v. tracer infusion study in acute pulmonary constrictive phase or convalescence. Data are presented as mean $\pm \mathrm{SEM}$ for the nine patients. Arginine enrichment in A.P.E. was lower $(p<0.05)$ during convalescence. Leucine enrichment was not different $(p>0.05)$ in acute $v s$ convalescent state of PPHN.

Thus, arginine fluxes were lower $(84.1 \pm 8.6)$ during acute pulmonary vasoconstriction, increasing to $125 \pm 13.2$ $\mu \mathrm{mol} \cdot \mathrm{kg}^{-1} \mathrm{~h}^{-1}(p<0.05)$ during recovery. When i.v. arginine intake is subtracted from the arginine flux, the "corrected," or endogenous, arginine flux was not significantly different between acute illness and convalescence $(71.5 \pm 6.0$ versus $\left.96.0 \pm 12.6 \mu \mathrm{mol} \cdot \mathrm{kg}^{-1} \mathrm{~h}^{-1}\right)$. Leucine fluxes, however, were $168.5 \pm 15.1$ versus $178.8 \pm 10.2$ and did not differ between the acute and convalescent states of PPHN, before or after "correction" for dietary intake. By using leucine as an index of whole body amino acid metabolism, the values of whole body protein turnover were obtained (Table 5). The mean rate of protein synthesis was $5.0 \pm 0.6 \mathrm{~g} \cdot \mathrm{kg} \cdot{ }^{-1} \mathrm{~d}^{-1}$ for the acute vasoconstrictive state of PPHN and $6.2 \pm 0.4$ for convalescence. Protein breakdown amounted to $6.0 \pm 0.7$ and $5.6 \pm$ 0.4 , respectively, for the acute and convalescent state. Protein balance was negative during PPHN and improved during convalescence $(p<0.05)$.

Table 6 summarizes the metabolic fate of the infused i.v. tracer of $\left[{ }^{15} \mathrm{~N}\right]$ arginine in relation to NO synthesis during PPHN. The level of ${ }^{15} \mathrm{~N}$ urinary enrichment, expressed in A.P.E., in the 24-h collection was $1.06 \pm 0.1$ for the acute hypertensive period, and this increased to $1.72 \pm 0.2$ ( $p<$ 0.01 ) during convalescence, despite the lower enrichment rate of arginine in the plasma at this time. The total amount of urinary nitrate excreted over the 24 -h period, beginning with the start of the tracer infusion, also increased by $66 \%$, to 44.11 $\pm 9.2 \mu \mathrm{mol} \cdot \mathrm{d}^{-1}(p<0.05)$, with convalescence. The urinary excretion rate of ${ }^{15} \mathrm{NO}_{3}{ }^{-}$during the 24 -h period also was increased from $0.29 \pm 0.07$ to $0.74 \pm 0.15 \mu \mathrm{mol} \cdot \mathrm{d}^{-1}(p<$ 0.01 ). This represented, therefore, a more than 2 -fold increase, markedly exceeding the degree of change in unlabeled nitrate output. Thus, plasma ${ }^{15} \mathrm{~N}$-labeled arginine was used for $\mathrm{NO}$ synthesis to a greater extent during convalescence. We calculate that the percentage of $\left[{ }^{15} \mathrm{~N}\right]$ guanidino-labeled arginine used for NO formation was increased from $0.53 \pm 0.13$ to 1.34 $\pm 0.27 \mu \mathrm{mol} \cdot \mathrm{d}^{-1}(p<0.01)$, as infants recovered from PPHN (Table 7). From this conversion rate and the plasma arginine 
Table 3. Plasma arginine fluxes and intake during acute illness and convalescence in patients with PPHN

\begin{tabular}{|c|c|c|c|c|c|c|}
\hline \multirow[b]{2}{*}{ Patient } & \multicolumn{2}{|c|}{ Arginine flux } & \multicolumn{2}{|c|}{ Arginine intake } & \multicolumn{2}{|c|}{ "Corrected" arginine flux } \\
\hline & Acute & Convalescent & Acute & Convalescent & Acute & Convalescent \\
\hline 1 & 45.5 & 115.2 & 0.0 & 18.1 & 45.5 & 97.1 \\
\hline 2 & 116.3 & 93.7 & 19.2 & 19.2 & 97.1 & 74.6 \\
\hline 3 & 104.4 & 112.0 & 21.7 & 30.6 & 82.7 & 81.50 \\
\hline 4 & 128.2 & 138.5 & 49.4 & 20.6 & 78.8 & 117.9 \\
\hline 5 & 86.2 & 123.8 & 0.0 & 30.6 & 86.2 & 93.2 \\
\hline 6 & 81.0 & 204.9 & 0.0 & 36.1 & 81.0 & 168.8 \\
\hline 7 & 66.8 & 74.6 & 0.0 & 36.4 & 66.8 & 38.5 \\
\hline 8 & 62.8 & 92.6 & 23.0 & 35.8 & 39.8 & 56.8 \\
\hline 9 & 65.1 & 169.0 & 0.0 & 33.8 & 65.1 & 135.2 \\
\hline Mean \pm SEM & $84.1 \pm 8.6 \dagger$ & $125.0 \pm 13.2$ & $12.6 \pm 5.4 \dagger$ & $29.0 \pm 2.4$ & $71.5 \pm 6.0 \$$ & $96.0 \pm 12.6$ \\
\hline
\end{tabular}

All values are $\mu \mathrm{mol} \cdot \mathrm{kg}^{-1} \mathrm{~h}^{-1}$.

$\ddagger$ Not significant.

$\dagger p<0.05$, difference acute from convalescence.

Table 4. Plasma leucine fluxes and intake during acute illness and convalescence in patients with PPHN

\begin{tabular}{|c|c|c|c|c|c|c|}
\hline \multirow[b]{2}{*}{ Patient } & \multicolumn{2}{|c|}{ Leucine flux } & \multicolumn{2}{|c|}{ Leucine intake } & \multicolumn{2}{|c|}{ "Corrected" leucine flux } \\
\hline & Acute & Convalescent & Acute & Convalescent & Acute & Convalescent \\
\hline 1 & 147.2 & 165.6 & 0.0 & 20.6 & 147.2 & 145.1 \\
\hline 2 & 156.3 & 166.9 & 21.8 & 21.8 & 134.5 & 145.2 \\
\hline 3 & 137.0 & 182.7 & 24.6 & 34.7 & 112.4 & 148.0 \\
\hline 4 & 153.0 & 130.4 & 56.1 & 23.4 & 96.9 & 107.0 \\
\hline 5 & 153.3 & 207.2 & 0.0 & 34.7 & 153.4 & 172.8 \\
\hline 6 & 295.1 & 205.0 & 0.0 & 43.2 & 295.1 & 161.8 \\
\hline 7 & 161.7 & 147.0 & 0.0 & 41.0 & 161.8 & 106.0 \\
\hline 8 & 152.3 & 168.5 & 26.4 & 41.1 & 125.9 & 127.5 \\
\hline 9 & 160.5 & 236.0 & 0.0 & 38.4 & 160.5 & 197.7 \\
\hline Mean \pm SEM & $168.5 \pm 15.1 \dagger$ & $178.8 \pm 10.2$ & $14.3 \pm 6 \neq$ & $33.2 \pm 2$ & $154.2 \pm 18 \dagger$ & $145.7 \pm 9$ \\
\hline
\end{tabular}

Values are $\mu \mathrm{mol} \cdot \mathrm{kg} \cdot{ }^{-1} \mathrm{~h}^{-1}$.

$\uparrow$ Not significant.

$\ddagger p<0.05$ difference acute from convalescent.

Table 5. Whole body protein turnover in patients with PPHN, during acute state and convalescence

\begin{tabular}{|c|c|c|c|c|c|c|}
\hline \multirow[b]{2}{*}{ Patients } & \multicolumn{2}{|c|}{ Protein synthesis $\left(g \cdot \mathrm{kg}^{-1} \cdot \mathrm{d}^{-1}\right)$} & \multicolumn{2}{|c|}{ Protein breakdown $\left(\mathrm{g} \cdot \mathrm{kg}^{-1} \cdot \mathrm{d}^{-1}\right)$} & \multicolumn{2}{|c|}{ Protein balance $\left(g \cdot \mathrm{kg}^{-1} \cdot \mathrm{d}^{-1}\right)$} \\
\hline & Acute & Convalescent & Acute & Convalescent & Acute & Convalescent \\
\hline 1 & 5.5 & 6.4 & 5.7 & 5.6 & -0.14 & 0.81 \\
\hline 2 & 5.7 & 6.1 & 5.2 & 5.6 & 0.49 & 0.53 \\
\hline 3 & 3.7 & 5.7 & 4.3 & 5.7 & -0.60 & 0.04 \\
\hline 4 & 3.5 & 4.1 & 3.7 & 4.4 & -0.18 & -0.03 \\
\hline 5 & 4.5 & 7.1 & 5.9 & 6.6 & -1.34 & 0.50 \\
\hline 6 & 9.6 & 7.4 & 11.4 & 6.2 & -1.77 & 1.13 \\
\hline 7 & 5.1 & 4.8 & 6.2 & 4.1 & -1.15 & 0.78 \\
\hline 8 & 3.9 & 5.6 & 4.8 & 4.9 & -0.92 & 0.73 \\
\hline 9 & 2.9 & 8.5 & 6.2 & 7.6 & -3.23 & 0.88 \\
\hline Mean \pm SEM & $5.0 \pm 0.6$ & $6.2 \pm 0.4$ & $6.0 \pm 0.7$ & $5.6 \pm 0.4$ & $-0.98 \pm 0.3^{*}$ & $0.59 \pm 0.1$ \\
\hline
\end{tabular}

$* p<0.05$ difference acute from convalescent.

flux, we estimate that the utilization rate of plasma arginine for NO production increased, with clinical improvement, from $10.33 \pm 2.2$ to $45.0 \pm 13.2 \mu \mathrm{mol} \cdot \mathrm{d}^{-1}(p<0.01)$. The creatinine clearance was $42.9 \pm 3.3$ and $40.4 \pm 2.6$ $\mathrm{ml} \cdot \mathrm{min} \cdot \mathrm{M}^{2}$, respectively, for acute PPHN and convalescence; it remained unchanged during both study periods and within the normal range for age. Arginine intake during convalescence was significantly correlated $\left(p<0.01 ; r^{2}=0.60\right)$ with the percentage of $\left[{ }^{15} \mathrm{~N}_{2}\right]$ arginine tracer used for NO formation (Fig. 2), but there was no correlation during acute PPHN.

\section{DISCUSSION}

We have investigated whole body arginine metabolism and NO production in critically ill newborns with PPHN. Despite the potential relevance of the L-arginine-NO pathway in the pathophysiology of pulmonary hypertension, no in vivo studies of the kinetics of arginine and NO have been conducted previously in this population. Due to ethical considerations, a healthy cohort was not investigated, therefore, each patient served as his/her own control during convalescence. The use of 
Table 6. Urinary ${ }^{15} \mathrm{~N}$ enrichment, total nitrate and ${ }^{15} \mathrm{NO}_{3}{ }^{-}$excretion in patients with PPHN and during convalescence

\begin{tabular}{|c|c|c|c|c|c|c|}
\hline \multirow[b]{2}{*}{ Patients } & \multicolumn{2}{|c|}{${ }^{15} \mathrm{~N}$ (A.P.E. in $24 \mathrm{~h}$ ) } & \multicolumn{2}{|c|}{ Urinary nitrate $\left(\mu \mathrm{mol} \cdot\right.$ day $\left.^{-1}\right)$} & \multicolumn{2}{|c|}{ Utinary ${ }^{15} \mathrm{NO}_{3}{ }^{-}\left(\mu \mathrm{mol} \cdot \mathrm{day}^{-1}\right)$} \\
\hline & Acute & Convalescent & Acute & Convalescent & Acute & Convalescent \\
\hline 1 & 0.3 & 0.5 & 6.3 & 19.3 & 0.01 & 0.09 \\
\hline 2 & 0.4 & 0.9 & 18.2 & 24.0 & 0.09 & 0.23 \\
\hline 3 & 0.9 & 2.2 & 20.5 & 21.2 & 0.18 & 0.47 \\
\hline 4 & 1.3 & 2.4 & 12.7 & 19.7 & 0.16 & 0.48 \\
\hline 5 & 0.9 & 1.3 & 57.6 & 75.2 & 0.57 & 1.02 \\
\hline 6 & 1.6 & 1.7 & 31.8 & 86.1 & 0.52 & 1.47 \\
\hline 7 & 1.0 & 2.5 & 22.7 & 28.6 & 0.23 & 0.74 \\
\hline 8 & 1.6 & 2.0 & 11.2 & 37.2 & 0.18 & 0.76 \\
\hline 9 & 1.2 & 1.5 & 57.8 & 85.3 & 0.69 & 1.36 \\
\hline Mean \pm SEM & $1.06^{*} \pm 0.1$ & $1.72 \pm 0.2$ & $26.56 \pm 6.0 \dagger$ & $44.11 \pm 9.2$ & $0.29 \pm 0.07^{*}$ & $0.74 \pm 0.15$ \\
\hline
\end{tabular}

Difference acute from convalescent.

${ }^{*} p<0.01$.

$\dagger p<0.05$.

Table 7. Percentage of $\left[{ }^{15} \mathrm{~N}_{2}\right]$ guanidino arginine tracer used for NO formation and conversion rate of plasma arginine to NO $\left(Q_{A r g} \rightarrow N O\right)$ during PPHN and convalescence

\begin{tabular}{|c|c|c|c|c|}
\hline \multirow[b]{2}{*}{ Patients } & \multicolumn{2}{|c|}{$\begin{array}{c}\%\left[{ }^{15} \mathrm{~N}_{2}\right] \text { Arg Trace infused } \\
\text { to NO }\left(\mu \mathrm{mol} \cdot \mathrm{d}^{-1}\right)\end{array}$} & \multicolumn{2}{|c|}{$\begin{array}{l}\text { Plasma arginine to NO } \\
\left(\mu \mathrm{mol}^{\circ} \text { day }^{-1}\right)\end{array}$} \\
\hline & Acute & Convalescent & Acute & Convalescent \\
\hline 1 & 0.03 & 0.17 & 0.36 & 4.71 \\
\hline 2 & 0.15 & 0.40 & 4.38 & 9.05 \\
\hline 3 & 0.32 & 0.78 & 8.01 & 21.09 \\
\hline 4 & 0.29 & 0.83 & 8.95 & 27.71 \\
\hline 5 & 0.98 & 1.77 & 20.47 & 52.79 \\
\hline 6 & 0.90 & 2.55 & 17.51 & 125.59 \\
\hline 7 & 0.40 & 1.26 & 6.52 & 22.69 \\
\hline 8 & 0.43 & 1.76 & 6.55 & 39.19 \\
\hline 9 & 1.29 & 2.52 & 20.30 & 102.63 \\
\hline Mean $\pm S E M$ & $0.53 \pm 0.13^{*}$ & $1.34 \pm 0.27$ & $10.33 \pm 2.2 \dagger$ & $45.0 \pm 13.2$ \\
\hline
\end{tabular}

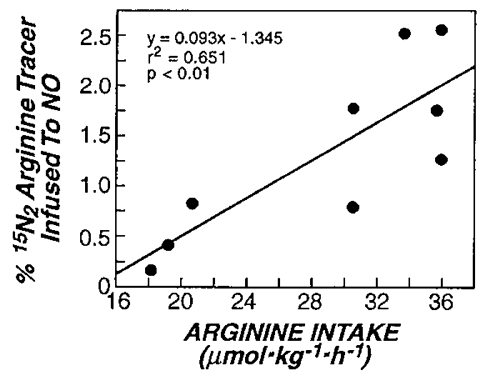

Figure 2. Relationship between arginine intake $\left(\mu \mathrm{mol} \cdot \mathrm{kg} \cdot{ }^{-1} \mathrm{~h} \cdot{ }^{-1}\right)$ and the percent of $\left[{ }^{15} \mathrm{~N}_{2}\right]$ arginine tracer infused to NO during convalescence.

ECMO in patient nos. 1, 2, 4, and 6 raised concerns regarding its effect on tracer kinetics. However, there was not difference in arginine kinetics, urinary enrichment, nitrate, and ${ }^{15} \mathrm{NO}_{3}{ }^{-}$ between the patients treated with ECMO and those who received conventional management $(p>0.05)$. Furthermore, leucine fluxes in the ECMO and conventionally treated group were comparable to values reported in healthy newborns of 164 \pm 28 and $201 \pm 16 \mu \mathrm{mol} \cdot \mathrm{kg} \cdot{ }^{-1} \mathrm{~h}^{-1}$ for the fast and fed state, respectively $(21,28)$.

This study reveals marked differences in whole body NO production and in the pattern of utilization of plasma arginine between the acute and convalescent phases in infants with PPHN. During the acute phase of the disease, the total urinary output of $\mathrm{NO}_{3}{ }^{-}$was about $60 \%$ of that during convalescence, suggesting a reduced conversion of the guanidino- $\mathrm{N}$ of arginine to NO and citrulline, via the action of NO synthase. The reduced urinary excretion of ${ }^{15} \mathrm{NO}_{3}{ }^{-}$after the i.v. infusion of ${ }^{15} \mathrm{~N}$-labeled arginine confirmed a diminished activity of the L-arginine-NO pathway, for ${ }^{15} \mathrm{NO}_{3}{ }^{-}$originates only from the $\left[{ }^{15} \mathrm{~N}\right]$ guanidino label of the arginine infused. Urinary nitrate excretion is dependent on adequate renal function, nitrate intake, and the presence of nitrate-producing bacteria $(29,30)$. The normal creatinine clearance values obtained in these patients, during acute pulmonary hypertension and convalescence, excluded the possibility of altered renal function during the acute, critically ill period and therefore decreased urinary excretion, rather than production of ${ }^{15} \mathrm{NO}_{3}{ }^{-}$. In addition, the patients received nitrate-free parenteral nutrition and only patients without infection were included in the study. Thus, the possibility of "contamination" during convalescence with exogenous sources of nitrate was ruled out.

With clinical improvement our patients received a higher intake of arginine, and the total arginine flux was higher in convalescent patients compared with that of acute illness. The leucine fluxes, however, were unchanged by the leucine intake and remained within the range of values reported in healthy newborns $(21,28)$. It would appear, then, that diet may have influenced arginine, but not leucine, metabolism. Furthermore, there was a significant correlation between dietary arginine intake during convalescence and the percentage of $\left[{ }^{15} \mathrm{~N}_{2}\right.$ ] arginine tracer utilized for NO synthesis (Fig. 2). It is conceivable, therefore, that the higher intake and higher plasma arginine flux may promote the formation of $\mathrm{NO}$, and that this also resulted in plasma arginine being the preferred substrate source for the eNOS reaction. An intervention study might help to determine whether this is so and also whether exogenous arginine would help to attenuate pulmonary hypertension. It should also be noted that the mean difference in arginine intakes between the acute and convalescent phases was about $16 \mu \mathrm{mol} \mathrm{kg} \cdot{ }^{-1} \mathrm{~h}^{-1}$, equivalent to $69 \mathrm{mg}$ arginine $\mathrm{kg} \cdot{ }^{-1} \mathrm{~d}^{-1}$ or a protein intake of about $1 \mathrm{~g} \cdot \mathrm{kg} \cdot{ }^{-1} \mathrm{~d}^{-1}$, which in both cases are nutritionally significant levels. Indeed protein balance was improved during convalescence. Also, a developmental matu- 
ration in arginine metabolism between d 3.1 versus d 6.9 of life would be difficult to sustain, because this process would selectively affect arginine and not leucine, which is an essential and nutritionally more "important" amino acid.

From our tracer data we are led to the conclusion that plasma arginine is used to a relatively lesser extent for NO synthesis during acute PPHN compared with that during convalescence. Whether the reduced in vivo activity of the eNOS reaction, which these data suggest, is due primarily to a change in the level and regulation of eNOS $(8,31,32)$ and/or to changes in the metabolism and tissue availability of arginine (13, 33-35) cannot be determined from this study. The differences in the relative utilization of plasma arginine for NO synthesis between acute and convalescent PPHN, coupled with the intake differences mentioned above, make it relevant to recall that there is extensive compartmentation of arginine metabolism in vivo, at the intracellular, intraorgan, and interorgan levels $(36-40)$, and although plasma arginine is made available during a complete turn of the urea cycle (Fig. 3), vascular endothelial cells, when stimulated, can exhibit a "direct" metabolic pathway whereby the citrulline produced by the action of the eNOS is directly converted to arginine thanks to the action of the argininosuccinate synthase and argininosuccinate lyase. Therefore, this L-arginine $\rightarrow$ NO-citrulline $\rightarrow$ L-arginine cycle enables intracellular arginine availability and NO production (41). An impairment in NO and citrulline production may also limit intracellular arginine availability, and this may lead to a greater dependence on plasma arginine and/or exogenous sources. It has been demonstrated in animal and human studies that, under some pathologic conditions, such as induced pulmonary hypertension (34), hypoxia $(13,14)$, and hypercholesterolemia $(11,42)$, the administration of L-arginine may reverse or attenuate vasoconstriction. These studies suggest the concept that arginine availability may become a rate-limiting step in NO formation. The factors that affect arginine utilization and availability have not been clearly established.

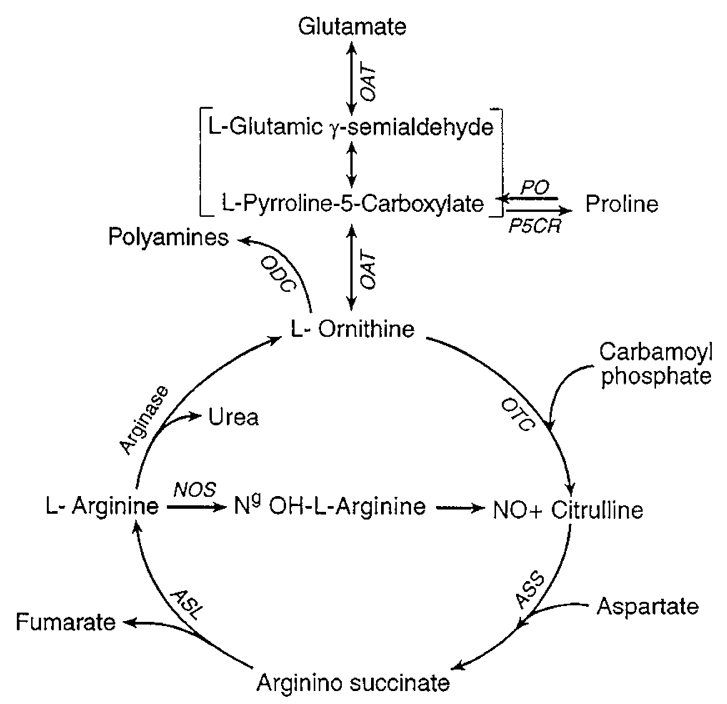

Figure 3. Schematic diagram describing the metabolic pathways of arginine. $N O S$, nitric oxide synthase; $O D C$, ornithine decarboxylase; $O A T$, ornithine amino transferase; $O T C$, ornithine transcarbamoylase; $A S S$, argininosuccinate synthase; $A S L$, argininosuccinate lyase; $P O$, proline oxidase; $P S C R$, pyrroline5-carboxylate reductase.
Due to the tight compartmentation of arginine metabolism, it is likely that different factors influence arginine availability at different levels. It is known that altered extracellular concentrations of L-lysine and L-ornithine competitively inhibit arginine transport; hence, extracellular concentrations of these amino acids can regulate cellular NO synthesis (43). The effect of hypoxemia or acid-base changes in plasma or intracellular arginine utilization remains to be established.

It also has been shown that rat liver arginase is inhibited by $N^{\mathrm{G}}$-hydroxy-L-arginine, an intermediate in the biosynthesis of NO from L-arginine (44), favoring the utilization of arginine as a substrate for eNOS. If this inhibition would occur also in lung arginase, a decreased formation of NO and citrulline would not only limit arginine availability, but also would limit inhibition of arginase, therefore channeling arginine toward urea and ornithine. There is evidence in recent investigations that in some pathophysiologic states, such as glomerulonephritis (45) and wound healing (46), there is a temporal expression of these two different pathways of $\mathrm{L}$-arginine metabolism ( $\mathrm{L}-$ arginine $\rightarrow$ ornithine pathway and the L-arginine $\rightarrow$ NOcitrulline pathway), depending on the pathophysiologic state. We speculate that, although it is possible that the etiology of pulmonary vasoconstriction and remodeling of the pulmonary arteries is perhaps multifactorial, involving growth factors (47), endothelins (48), and nitric oxide (4), a preferential direction of arginine metabolism toward the formation of ornithine and polyamines resulting in smooth muscle proliferation and remodeling of the pulmonary arteries, with a concomitant fall in the activity of the L-arginine-NO-citrulline pathway leading to pulmonary vasoconstriction and hypertension, may contribute to this pathology (Fig. 4). In view of the limitations in the interpretation of whole body metabolic tracer studies, further investigations aimed to assess the in vivo quantitative significance and relationships among these pathways of arginine metabolism during pulmonary hypertension at the pulmonary level are necessary. Estimation of the stoichiometric L-arginine $\rightarrow \mathrm{NO}$-citrulline pathway by measurement of labeled $\left[{ }^{15} \mathrm{~N}\right]$ citrulline and investigations of the ornithinepolyamine pathway by measurement of ${ }^{2} \mathrm{H}_{2}$-labeled polyamines should further improve our understanding of the complex interactions between arginine metabolism, NO synthesis, and the pathophysiologic events that take place in PPHN. Although additional, comparable data in normal healthy infants would be strongly desirable, ethical considerations regarding the use of invasive studies in healthy newborns excluded this possibility.

In summary, we describe here, apparently for the first time, whole body arginine metabolism and NO production in pa-

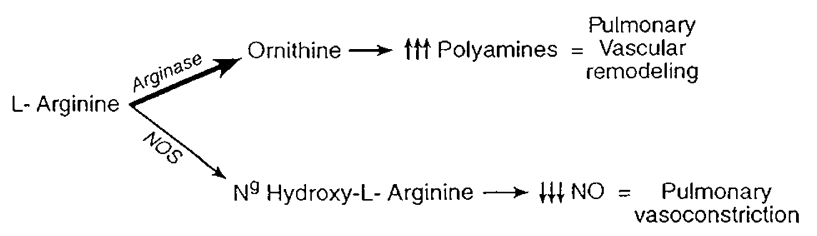

Figure 4. Schematic diagram that depicts a proposed alteration of arginine metabolism during PPHN. Different arrow size from L-arginine indicates a greater activity of arginase over NOS. 
tients with PPHN. From these observations we conclude that plasma arginine utilization for whole body NO synthesis is decreased during the acute vasoconstrictive state of PPHN and suggest the concept that arginine availability may become an important factor in NO formation. We are fully aware that the present study is limited by the variable clinical conditions and nutritional support of our patients, the reduced sample size, and the absence of healthy controls. Although these difficulties are often present in clinical investigations involving critically ill patients, we believe that, given the biological relevance of the $\mathrm{L}$-arginine-NO pathway, it is important to begin to explore in vivo quantitative aspects of arginine metabolism in these patients. We propose that further studies at the pulmonary level will yield organ-specific information regarding the metabolism of arginine during PPHN.

Acknowledgments. The authors thank Drs. Warren Zapol, Mary Etta King, Lars Erickson, and Jay Roberts for their helpful comments, and Alice Traudt for her secretarial assistance.

\section{REFERENCES}

1. Levin DL, Heyman MA, Kitterman JA 1976 Persistent pulmonary hypertension of the newborn. J Pediatr 89:626-629

2. Moncada S, Radomski M, Palmer R 1988 Endothelium derived relaxing factor. Biochem Pharmacol 37:2495-2501

3. Moncada S 1992 The L-arginine:nitric oxide pathway. Acta Physiol Scand 145:201227

4. Fineman JR, Wong J, Morin FC, Wilt LM, Soifer SJ 1994 Chronic nitric oxide inhibition in utero produces persistent pulmonary hypertension in newborn lamb. $J$ Clin Invest 93:2675-2683

5. Davidson D, Elmerdash A 1990 Endothelium-derived relaxing factor: Presence in pulmonary and systemic arteries of the newborn guinea pig. Pediatr Res 27:128-132

6. Abman SH, Chatfield BA, Hall SL, McMurtog IF 1990 Role of endothelium-derived relaxing factor during transition circulation at birth. Am J Physiol 259:H1921-H1927

7. Kinsella JP, McQueston JA, Rosenberg AA, Abman SH 1992 Hemodynamic effects of exogenous nitric oxide in ovine transitional pulmonary circulation. Am J Physiol 263:H875-H880

8. Ignarro LJ 1991 Signal transduction mechanisms involving nitric oxide. Biochem Pharmacol 41:485-490

9. Marletta MA, Yoon PS, Iyengar R, Leaf CD, Wishnok JS 1988 Macrophage oxidation of L-arginine to nitrite and nitrate:nitric oxide is an intermediate. Biochemistry 27:8706-87011

10. Green LC, de Luzuriaga KR, Wagner DA, Rand W, Istfan N, Young VR, Tannenbaum SR 1981 Nitrate biosynthesis in man. Proc Natl Acad Sci USA 82:7764-7767

11. Cooke JP, Dzau JN, Creager MA 1991 Endothelial dysfunction in hypercholesterolemia is corrected by L-arginine. Basic Res Cardiol 86:173-181

12. McNamara D, Bedi B, Aurora H, Tena L, Ignarro L, Kadowitz P, Akers D 1993 L-Arginine inhibits balloon catheter-induced internal hyperplasia. Biochem Biophys Res Commun 193:291-294

13. Adnot S, Eddahibi S, Raffestin B 1992 Loss of endothelium-dependent relaxation during chronic hypoxic pulmonary hypertension: Recovery on return to room air or after treatment with L-arginine. In: Moncada S, Marletta M, Hibbs J, Higgs EA (eds) The Biology of Nitric Oxide-I. Portland Press, London, pp 32-34

14. Fineman JR, Chang R, Soifer J 1991 L-Arginine, a precursor of EDRF in vitro, produces pulmonary vasodilation in lamb. Am J Physiol 261:H563-H569

15. Atkinson JE, Olson JW, Altiere R, Gillespie MN 1987 Evidence that hypoxic pulmonary vascular remodeling in rats is polyamine dependent. J Appl Physiol 62:1562-1568

16. Shiao RT, Kostenbauder HB, Olson JW, Gillespie MN 1990 Mechanisms of lung polyamine accumulation in chronic hypoxic pulmonary hypertension. Am $\mathrm{J}$ Physio 259:L351-L358

17. Olson JW, Hacker AD, Atkinson JE, Altiere RJ, Gillespie MN 1986 Polyamine content in rat lung during development of hypoxia-induced puImonary hypertension. Biochem Pharmacol 35:714-716

18. Georgieff M, Mills M, Bhatt P 1989 Validation of two scoring systems which assess the degree of physiologic instability in critically ill newborn infants. Crit Care Med $17: 17-21$
19. Keene AR, Cullen D 1983 Therapeutic intervention score system. Crit Care Med $11: 1-3$

20. Stolar C, Snedcor SM, Bartlett RH 1991 Extracorporeal membrane oxygenation and neonatal respiratory failure: Experience from the Extracorporeal Life Support Organization. J Pediatr Surg 26:563-571

21. Denne SC, Kalhan SC 1987 Leucine metabolism in human newborns. Am J Physiol 253:E608-E615

22. Castillo L, Yu M, Marchini S, Chapman TE, Sanchez M, Young VR, Burke JT 1994 Phenylalanine and tyrosine kinetics in critically ill children with sepsis. Pediatr Res 35:580-588

23. Castillo L, deRojas TC, Chapman TG, Burke JF, Tannenbaum SR, Young VR 1993 Splanchnic metabolism of dietary arginine in relation to nitric oxide synthesis in normal adult man. Proc Natl Acad Sci USA 90:193-197

24. Green LC, Wagner DA, Glogowski J, Skipper PL, Wishnok JS, Tannenbaum SR 1982 Analysis of nitrate, nitrite and [ $\left.{ }^{15} \mathrm{~N}\right]$ nitrate in biological fluids. Anal Biochem 126:131-138

25. Matthews DE, Motel KJ, Rohrbaugh DK, Burke JF, Young VR, Bier DM 1980 Measurement of leucine metabolism in man from a primed, constant infusion of $\mathrm{L}-\left[1-{ }^{13} \mathrm{C}\right]$ leucine. Am J Physiol 238:E473-E479

26. Kandel H, Darwish O, Hammand S, Zagloul N, Halliday D, Millward J 1991 Nitrogen balance and protein turnover during the growth failure in newly born low-birth-weight infants. Am J Clin Nutr 53:1411-1417

27. SAS/STAT Guide for Personal Computers, 9th ed 1991 SAS Institute, Cary, NC

28. Denne SC, Rossi E, Kalhan SC 1991 Leucine kinetics during feeding in normal newborns. Pediatr Res 30:23-27

29. Castillo L 1994 Sources of nitrates and nitrites in neonates with sepsis. [letter] J Pediatr 3:488

30. Hibbs J, Westenfelder C, Taintor R, Vavrin Z, Kablitz C, Baranowski R, Ward J, Menlove R, McMurry M, Kushner J, Samlowski W 1992 Evidence of cytokineinducible nitric oxide synthesis from $\mathrm{L}$-arginine in patients receiving interleukin-2 therapy. J Clin Invest 89:867-877

31. Nathan C 1992 Nitric oxide as a secretory product of mammalian cells. FASEB J $6: 3051-3064$

32. Dinh-Xuan AT, Higgenbottam TW, Clelland CA, Pepke-Zaba J, Cremona G, But AY, Large SR, Wells FC, Wallwork J 1991 Impairment of endothelium-dependent pulmonary artery relaxation in chronic obstructive lung disease. $N$ Engl J Med 324:1539-1547

33. Gold ME, Wood KS, Byrns RE, Buga GM, Ignarro LJ 1990 L-Arginine-dependent vascular smooth muscle relaxation and cGMP formation. Am J Physiol 259:H1813H1821

34. Fineman J, Chang R, Soifer S 1992 EDRF inhibition augments pulmonary hypertension in intact newborn lamb. Am J Physiol 262:H1365-H1371

35. Gold ME, Bush PA, Ignarro LJ 1989 Depletion of arterial L-arginine causes reversible tolerance to endothelium-dependent relaxation. Biochem Biophys Res Commun 164:714-721

36. Dhanakoti SN, Brosnan ME, Herzberg GR, Brosnan JT 1992 Cellular and subcellular localization of enzymes of arginine metabolism in rat kidney. Biochem J 281:1-7

37. Brosnan JT, Dhanakoti SN, Skanes SM, Wu G, Herzberger GR, Brosnan ME 1992 Endogenous arginine synthesis. In: Moncada S, Marletta M, Hibbs J, Higgs EA (eds) The Biology of Nitric Oxide-II. Portland Press, London, pp 32-34

38. Castillo L, Branch S, Chapman T, Yu YM, Young VR 1994 Plasma arginine kinetics in adult man: Response to an arginine free diet. Metabolism 43:114-122

39. Featherston WR, Rogers QR, Freedland RA 1973 Relative importance of kidney and liver in synthesis of arginine by the rat AM J Physiol 224:127-129

40. Castillo L, Chapman T, Yu Yong M, Ajami A, Young VR 1993 Dietary arginine uptake by the splanchnic region in adult humans. Am J Physiol 265:E532-E539

41. Hattori Y, Campbell EB, Gross SS 1994 Argininosuccinate synthetase mRNA and activity are induced by immunostimulants in vascular smooth muscle. $\mathrm{J}$ Biol Chem 269:9405-9408

42. Drexler H, Zeiher AM, Meinzer K, Hanjorg J 1991 Correction of endothelial dysfunction in coronary microcirculation of hypercholesterolaemic patients by Larginine. Lancet 338:1546-1549

43. Bogle RG, Baydoun AR, Pearson JD, Moncada S 1992 L-Arginine transport is increased in macrophages generating nitric oxide. Biochem $J$ 284:15-18

44. Daghigh F, Fukuto JM, Ash DE 1994 Inhibition of rat liver arginase by an intermediate in NO biosynthesis, $N^{G}$-hydroxy-L-arginine: Implications for the regulation of nitric oxide biosynthesis by arginase. Biochem Bioph Res Commun 202:174-180

45. Jansen A, Lewis S, Cattell V, Cook HT 1992 Arginase is a major pathway of L-arginine metabolism in nephritic glomeruli. Kidney Int 42:1107-1112

46. Albina JE, Mills CD, Henry Jr WL 1990 Temporal expression of different pathways of $\mathrm{L}$-arginine metabolism in healing wounds. J Immunol 144:3877-3880

47. Perkett EA, Pelton RW, Meyrick B, Gold LI, Miller DA 1994 Expression of transforming growth factor beta mRNAs and proteins in pulmonary vascular remodeling in the sheep air embolization model of pulmonary hypertension. Am J Respir Cell Mol Biol 11:16-21

48. Giaid A, Yanagisawa M, Langleben D, Michel RP, Levy R, Shennib H, Kimura S, Masaki T, Duguid WP, Steward DJ 1993 Expression of endothelin-1 in the lungs of patients with pulmonary hypertension. N Engl J Med 328:1732--1739 